\title{
AMCoR
}

Asahikawa Medical College Repository http://amcor. asahikawa-med. ac. jp/

NEUROBIOLOGY OF DISEASE (2004) 17-1:108-113.

Neuronal RNA oxidation is a prominent feature of familial Alzheimer disease

Nunomura, A; Chiba, S; Lippa, CF; Cras, P; Kalaria, RN; Takeda, A; Honda, K; Smith, MA; Perry, G 


\section{Neuronal RNA Oxidation Is a Prominent Feature of Familial Alzheimer Disease}

\section{Akihiko Nunomura ${ }^{1}$, Shigeru Chiba ${ }^{1}$, Carol F. Lippa ${ }^{2}$, Patrick Cras ${ }^{3}$, Rajesh N. Kalaria ${ }^{4}$,} Atsushi Takeda ${ }^{5}$, Kazuhiro Honda ${ }^{6}$, Mark A. Smith $^{6}$, and George Perry ${ }^{6}$

${ }^{1}$ Department of Psychiatry and Neurology, Asahikawa Medical College, Asahikawa 078-8510, Japan;

${ }^{2}$ Department of Neurology, Drexel University College of Medicine, Philadelphia, Pennsylvania 19129, USA;

${ }^{3}$ Laboratory of Neuropathology, Born Bunge Foundation, University of Antwerp, B-2610 Antwerp, Belgium;

${ }^{4}$ Institute for Ageing and Health, Wolfson Unit, Newcastle General Hospital, Newcastle upon Tyne NE4 6BE, UK;

${ }^{5}$ Department of Neurology, Tohoku University School of Medicine, Sendai 980-8575, Japan;

${ }^{6}$ Institute of Pathology, Case Western Reserve University, Cleveland, Ohio 44106, USA

Abbreviated Title: RNA oxidation in familial Alzheimer disease

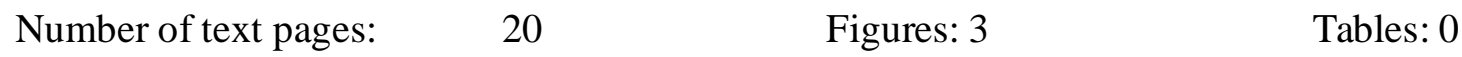

Corresponding Author:

Akihiko Nunomura, MD, PhD

Department of Psychiatry and Neurology, Asahikawa Medical College

Higashi 2-1-1-1, Midorigaoka, Asahikawa 078-8510, Japan

Phone: $+81-166-68-2473$

FAX: +81-166-68-2479

E-mail: nuno@asahikawa-med.ac.jp 
Abstract

An in situ approach was used to identify the oxidized RNA nucleoside, 8-hydroxyguanosine (8OHG) in the frontal cortex of familial Alzheimer disease (FAD) with a mutation in presenilin-1 (PS-1) or amyloid $\beta$ protein precursor $(\mathrm{A} \beta \mathrm{PP})$ gene $(\mathrm{n}=13$, age $47-81$ y). Neurons with marked $8 \mathrm{OHG}$ immunoreaction in the cytoplasm were widely distributed in the superior/middle frontal gyrus of FAD. Relative intensity measurements of neuronal 8OHG immunoreactivity showed that there was a significant increase in FAD compared with controls (n $=15$, age $59-81 \mathrm{y}$ ), while there was no difference in relative $8 \mathrm{OHG}$ between the PS- 1 and the A $\beta$ PP FAD. Interestingly, a presymptomatic case carrying a PS-1 mutation showed a considerable level of relative $8 \mathrm{OHG}$, and the increased levels of neuronal $8 \mathrm{OHG}$ in FAD were more prominent in cases with lower $\%$ area of $A \beta 42$ burden. These results suggest that oxidative stress is an early event involved in the pathological cascade of FAD.

K ey words: amyloid $\beta$ protein precursor, familial Alzheimer disease; 8-hydroxyguanosine; oxidative stress; presenilin; RNA 
Numerous studies have now established the association of neuronal oxidative stress with major neurodegenerative disorders such as Alzheimer disease (AD) (reviewed in Perry et al., 1998; Markesbery and Carney, 1999; Smith et al., 2000) and Parkinson disease (reviewed in Jenner, 1998; Zhang et al., 2000). We have reported RNA oxidation in vulnerable neurons of sporadic type of AD (Nunomura et al., 1999; 2001), Parkinson disease (Zhang et al., 1999), dementia with Lewy bodies (Nunomura et al., 2002) as well as Down syndrome (Nunomura et al., 2000), which suggests links between oxidative stress and not only age-associated degenerative diseases but also neurodegeneration due to genetic factors.

In this study, we used an in situ approach to identify the oxidized RNA nucleoside, 8-hydroxyguanosine $(8 \mathrm{OHG})$ in the cerebral cortex of familial $\mathrm{AD}$ (FAD) with a mutation in presenilin-1 (PS-1) or amyloid $\beta$ protein precursor (A $\beta$ PP) gene. Neurons with marked $8 \mathrm{OHG}$ immunoreaction in the cytoplasm were widely distributed in the cerebral cortex of FAD. Importantly, a presymptomatic case carrying a PS-1 mutation (Lippa et al., 1998) showed a considerable level of neuronal 8OHG. Moreover, semiquantitative analysis showed that the increased levels of neuronal $8 \mathrm{OHG}$ in FAD were more prominent in cases with lower amount of amyloid $\beta(\mathrm{A} \beta)$ which was immunolabeled with an end-specific antibody for the A $\beta 1-42(\mathrm{~A} \beta 42)$, as we showed in individuals with Down syndrome (Nunomura et al., 2000). These results suggest that oxidative stress is involved in the pathological cascade of FAD especially as an early stage event of the cascade. 


\section{M aterials and methods}

Tissue.

Brain tissue was obtained at autopsy from 13 clinically- and pathologically- confirmed cases of FAD according to the CERAD criteria ( 2 males and 11 females; ages 47-81 years, average 59). Eleven females of the FAD group (ages 47-81 years, average 59) were members of families possessing a PS-1 gene mutation and the other 2 males of the FAD group (ages 57 and 58 years) were members of families possessing an A $\beta$ PP gene mutation. Mutations in PS-1 gene in these subjects were found on M146L $(n=1)$, A246E $(n=4)$, L286V $(n=1)$ and C410Y $(n=5)$, and mutations in AßPP gene were found on KM670, 671NL (Swedish mutation; $n=1$ ) and A692G (Flemish mutation; $\mathrm{n}=1$ ). All these FAD subjects died from pneumonia except for a case whose information about cause of death was not available. Another 51 years old male was a member of a family with a PS-1 gene mutation (A246E), who died from myocardial infarction and had shown no clinical symptoms of dementia immediately before death (Lippa et al., 1998). As for the controls, we investigated a consecutive series of 15 subjects without dementia ( 7 males and 8 females; ages 59-81 years, average 66). Causes of death of these controls were internal malignancy $(n=9)$, leukemia $(n=2)$, cardiac failure $(n=3)$, and unknown $(n=1)$. Postmortem intervals prior to fixation were 2-19 $\mathrm{h}$ (average 8) in the FAD group, $14 \mathrm{~h}$ in the presymptomatic case with PS-1 gene mutation, and 3-20 h (average 9) in controls. Duration of dementia was known from clinical records in 12 cases of FAD as 5-25 years (average 11). Slices of the frontal cortex (the superior/middle frontal gyrus) and/or the temporal cortex (the inferior temporal/occipitotemporal gyrus) from all the subjects were fixed in neutral formalin, dehydrated through graded ethanol followed by xylene, and embedded in paraffin. Six-micron thick sections were cut, and mounted on Silane ${ }^{\circledR}($ Sigma, St. Louis, MO)-coated glass slides. 
Immunocytochemistry and Antibodies.

Following deparaffinization with xylene, sections were hydrated through graded ethanol. Endogenous peroxidase activity in the tissue was eliminated by a 30 min incubation with $3 \%$ $\mathrm{H}_{2} \mathrm{O}_{2}$ in methanol and non-specific binding sites were blocked in a 30 min incubation with $10 \%$ normal goat serum in Tris-buffered saline (150 mM Tris-HCl, $150 \mathrm{mM} \mathrm{NaCl}, \mathrm{pH}$ 7.6). To detect oxidized nucleosides, we used a mouse monoclonal antibody against 8OHG, 1F7 (Yin et al., 1995) (1:30; Trevigen, Gaithersburg, MD), after treatment with $10 \mu \mathrm{g} / \mathrm{ml}$ proteinase $\mathrm{K}$ (Boehringer Mannheim, Indianapolis, IN) in phosphate buffered saline $(\mathrm{pH}=7.4$ ) for $40 \mathrm{~min}$ at $37^{\circ} \mathrm{C}$. Immunostaining was developed by the peroxidase-antiperoxidase procedure (Sternberger, 1986) by using $0.75 \mathrm{mg} / \mathrm{ml} 3,3^{\prime}$-diaminobenzidine cosubstrate in $0.015 \% \mathrm{H}_{2} \mathrm{O}_{2}, 50 \mathrm{mM}$ Tris- $\mathrm{HCl}$, pH 7.6 for exactly $10 \mathrm{~min}$. The specificity of $1 \mathrm{~F} 7$ to $8 \mathrm{OHG}$ was confirmed by primary antibody omission or by absorption with purified $8 \mathrm{OHG}$ (Cayman Chemical, Ann Arbor, MI) (Nunomura et al., 1999). Although 1F7 recognizes RNA-derived $8 \mathrm{OHG}$ as well as DNA-derived 8-hydroxydeoxyguanosine with similar binding affinities (Yin et al., 1995), we have confirmed that 1F7 immunolabeling in neurons in sporadic AD is predominantly in RNA by the pretreatment with DNase or RNase (Nunomura et al., 1999) as well as by immunoelectronmicroscopy, which showed most $8 \mathrm{OHG}$ is present in the endoplasmic reticulum (Nunomura et al., 2001). For FAD cases, additional sections were pretreated with RNase-free DNase I (10 U/ $\mu \mathrm{l}$ for $2 \mathrm{~h}$ at $37^{\circ} \mathrm{C}$; Roche, Mannheim, Germany) or DNase-free RNase $(0.5 \mu \mathrm{g} / \mu \mathrm{l}$ for $2 \mathrm{~h}$ at $37^{\circ} \mathrm{C}$; Boehringer Mannheim) after the proteinase-K treatment. For the detection of $\mathrm{A} \beta$ deposition in FAD cases, we used either of mouse monoclonal antibody, BC05 (1:1000; gift of Fukumoto, H., Takeda Chemical Industries, Osaka, Japan) specific for the carboxyl terminus of 
A 1 1-42 (Aß42), or BA27 (1:3,500; gift of Fukumoto, H.) specific for the carboxyl terminus of $\mathrm{A} \beta 1-40(\mathrm{~A} \beta 40)$, with a 5 min pretreatment of $70 \%$ formic acid.

Relative scale of $8 \mathrm{OHG}$ and $\mathrm{A} \beta$ deposition

All measurements were performed in the layer III of the cerebral cortex (the superior/middle frontal gyrus and/or the inferior temporal/occipitotemporal gyrus) using a Q500IW-EX Image Processing and Analysis System (Leica) linked to a SONY CCD Camera (XC-75CE) mounted on a Nikon MICROPHOT-FX microscope. The intensity of immunoreaction with 1F7 was evaluated by measuring the average optical density in an area comprising the cytoplasm and nucleus, as we described previously (Nunomura et al., 1999). Three adjacent fields (each field = $460 \mu \mathrm{m} \times 428 \mu \mathrm{m}$ ) were selected, and in each field of the video camera, 5 pyramidal neurons sectioned near their equator, based on a section plane that included the nucleolus, were selected and outlined manually so that of the area of the nucleus to cytoplasm was rather constant. The nucleus was included because damage to RNA was nuclear as well as cytoplasmic. The average optical density measurement was obtained for each of the 3 fields and averaged. Finally, the optical density value was corrected for background by subtracting the optical density of the white matter on the same section. The superior/middle frontal gyrus was available in all 13 FAD cases, while the inferior temporal/occipitotemporal gyrus was available in all 19 controls. Both brain regions were available in two controls and an additional centenarian without dementia, in which levels of the relative $8 \mathrm{OHG}$ were similar in both brain regions. In these cases, the ratio of relative $8 \mathrm{OHG}$ in the frontal cortex to that in the temporal cortex was $0.78,0.84$ and 1.13 (average 0.92 ), which meant that the regional difference in relative neuronal $80 \mathrm{OHG}$ between the frontal and temporal cortices were virtually negligible in controls. Therefore, we used data from the 
superior/middle frontal gyrus of FAD cases and the inferior temporal/occipitotemporal gyrus of controls for comparison.

For the measurement of the extent of $\mathrm{A} \beta 42$ or $\mathrm{A} \beta 40$ deposition in FAD cases, three adjacent fields (each field $=624 \mu \mathrm{m} \times 580 \mu \mathrm{m}$ ) were selected to include the same area used to measure 1F7 immunoreactivity in an adjacent serial section. The area of $A \beta 42$ or $A \beta 40$ deposits was determined with gray scale thresholding according to the methods described previously (Hyman et al., 1993). The sum of the areas of $A \beta 42$ or $A \beta 40$ deposits was divided by the total area to give the $\% \mathrm{~A} \beta 42$ or $\% \mathrm{~A} \beta 40$ burden.

All measurements were done under the same optical and light conditions as well as using an electronic shading correction to compensate for any unevenness that might be present in the illumination. Statistical analysis was performed with Mann-Whitney U-test and linear regression analysis, using StatView 5.0 program (Abacus Concepts, Berkeley, CA). 


\section{Results}

In cases of FAD, $8 \mathrm{OHG}$ immunoreactivity was prominent in the neuronal cytoplasm in the superior/middle frontal gyrus (Figs. 1A-C). Neuronal 8OHG immunoreaction was widely distributed throughout the cortical layers (Fig. 1A) while in controls, staining was very low (Fig. 1E). Pyramidal neurons of larger size in the superior/middle frontal gyrus tended to show higher immunointensity of $8 \mathrm{OHG}$ in each case of $\mathrm{FAD}$, although individual variation of immunointensity among FAD cases was observed. Moderately positive immunoreaction of neuronal 8OHG was observed in a presymptomatic case carrying a PS-1 gene mutation (Fig. 1D).

To investigate whether the immunoreaction with the 1F7 antibody was derived from oxidized RNA or oxidized DNA or both, we performed nuclease treatment before the immunostaining with 1F7. The immunoreaction in the sections of FAD was diminished greatly by the DNase free-RNase pretreatment (Figs. 2A, B) but only slightly by the RNase free-DNase pretreatment (Figs. 2C, D), as we demonstrated in the sections of sporadic AD and DLB (Nunomura et al., 1999; 2002). Therefore, not only in sporadic AD and DLB but also in FAD, RNA is a major site of nucleic acid oxidation.

Relative scale measurements of the $8 \mathrm{OHG}$ immunoreactivity using a computer-assisted image analysis system demonstrated that the increase was significant in FAD when compared with a control group (Fig. 3A). Because the 8OHG immunoreactivities tend to show an age-dependent increase in non-demented individuals (Nunomura et al., 1999), the significant increase in the $8 \mathrm{OHG}$ immunoreactivity in FAD cases (the mean age, 59 years) compared with controls (the mean age, 66 years) cannot be explained by the difference in age of subjects between the groups. Neither, these results cannot be explained by neuronal shrinkage, because 
the average cell profile area remained unchanged between FAD cases $\left(161 \mu \mathrm{m}^{2}\right)$ and controls $\left(148 \mu \mathrm{m}^{2}\right)$. Similar levels of relative $8 \mathrm{OHG}$ were demonstrated between the PS-1 and the A $\beta$ PP FAD [the average of the relative $8 \mathrm{OHG}=10.2$ (arbitrary units) and 9.6, respectively]. Interestingly, a presymptomatic case carrying a PS-1 gene mutation showed a considerable level of relative $8 \mathrm{OHG}$ (Fig. $3 \mathrm{~A}$ ). Levels of the relative $8 \mathrm{OHG}$ immunoreactivity were not related to postmortem intervals among FAD cases ( $\mathrm{p}>0.9$ by linear regression analysis) as well as among controls $(p>0.9)$. Furthermore, an agonal state before death also failed to alter the relative 8OHG immunoreactivity. We found similar average values for the relative $8 \mathrm{OHG}$ immunoreactivity in controls who died from internal malignancy $(\mathrm{n}=9$, relative $8 \mathrm{OHG}=4.7$, leukemia $(\mathrm{n}=2$, relative $8 \mathrm{OHG}=7.9)$, heart failure $(\mathrm{n}=3$, relative $8 \mathrm{OHG}=5.9)$, and unknown ( $\mathrm{n}=1$, relative $8 \mathrm{OHG}=4.9)$, as we showed in other series of controls (Nunomura et al., 1999).

When we investigated relationship between $\%$ area of $A \beta 42$ or $A \beta 40$ burden and relative $8 \mathrm{OHG}$ levels in FAD, we found a significant inverse correlation between $\%$ area of $\mathrm{A} \beta 42$ burden and relative $8 \mathrm{OHG}$ levels, but no significant correlation between $\%$ area of $\mathrm{A} \beta 40$ burden and relative $8 \mathrm{OHG}$ levels (Figs 3B, C), as we observed in Down syndrome (Nunomura et al., 2000). In controls, only 7 cases showed A $\beta 42$ burden and only 3 cases showed $A \beta 40$ burden. No apparent relationship between \%area of $A \beta 42$ or $A \beta 40$ and the levels of neuronal $80 H G$ was detected in control subjects (data not shown). 


\section{Discussion}

Recently, an increasing number of in vitro and in vivo studies have suggested that oxidative stress is involved in the pathogenesis of $\mathrm{AD}$ and has an involvement in FAD with $\mathrm{A} \beta \mathrm{PP}, \mathrm{PS}-1$, or PS-2 gene mutation. Indeed, increased oxidative stress, elevated vulnerability to oxidative stress-induced cell death and /or reduced antioxidant defenses have been demonstrated in: (i) cell lines expressing mutant human A $\beta$ PP, PS-1, or PS-2 (Guo et al., 1997; Eckert et al., 2001; Hashimoto et al., 2002; Marcues et al., 2003); (ii) transgenic mice expressing mutant human A $\beta$ PP and/or PS-1 as well as knock in mice expressing mutant human PS-1 (Smith et al., 1998; Guo et al., 1999; Leutner, et al., 2000; Takahashi et al., 2000; Matsuoka, et al., 2001; Praticò, et al., 2001; LaFontaine et al., 2002); (iii) fibroblasts and lymphoblasts from FAD patients with AßPP or PS-1 gene mutation (Cecchi et al., 2002); and (iv) cerebral cortex of autopsied brain samples from patients with A $\beta$ PP gene mutation (Bogdanovic et al., 2001). The findings presented here represent the first evidence of increased oxidative damage to RNA in the cerebral cortex neurons of FAD, a finding previously made for the cerebral cortex neurons in sporadic $\mathrm{AD}$ and DLB (Nunomura et al., 1999; 2001; 2002) as well as for the substantia nigra neurons of Parkinson disease (Zhang et al., 1999). Therefore, RNA oxidation is a common phenomenon in vulnerable neurons of sporadic and familial types of $\mathrm{AD}$ as well as some disorders classified in the category of synucleinopathy. A recent biochemical study has revealed that some mRNA species are selectively oxidized in the cerebral cortex of $\mathrm{AD}$, and as a biological consequence, abnormal processing of proteins occurred to the oxidized mRNAs when they are expressed in cell lines (Shan et al., 2003). These findings suggest that RNA oxidation itself is directly associated with neuronal deterioration instead of harmless epiphenomenon during the process of neurodegeneration. 
Interestingly, a presymptomatic case carrying a PS-1 mutation, whose autopsied cerebral cortex exhibited substantial amount of $\mathrm{A} \beta 42$ deposition but no $\mathrm{A} \beta 40$ deposition (Lippa et al., 1998), showed a considerable level of neuronal RNA oxidation. This observation clearly suggests an early involvement of oxidative stress in the pathological cascade of FAD, which corresponds with our previous finding in Down syndrome cases where neuronal RNA oxidation precedes $A \beta$ deposition (Nunomura et al., 2000). The early involvement of oxidative stress in FAD is supported also by experiments examining transgenic mice expressing human A $\beta P P$ with FAD mutation and showing increased lipid peroxidation prior to $\mathrm{A} \beta$ plaque formation (Praticò, et al., 2001).

Furthermore, we found a significant inverse correlation of $\mathrm{A} \beta 42$ burden, but not $\mathrm{A} \beta 40$ burden, with neuronal RNA oxidation. Again, this observation is completely coincident with the results of our previous study on Down syndrome (Nunomura et al., 2000). Because A $\beta 42$ deposition is an upstream event in the pathological cascade of FAD (Iwatsubo et al., 1994; Kalaria et al., 1996; Lippa et al., 1998), early involvement of oxidative stress is suggested by the association of $A \beta 42$ burden with the levels of neuronal RNA oxidation. We may be able to explain the inverse correlation between $\mathrm{A} \beta 42$ burden and neuronal RNA oxidation when we consider roles of transition metals such as copper and iron, efficient catalysts of oxidation, and zinc, a redox-inert antioxidant that are significantly elevated in the neocortex and especially enriched in $\mathrm{A} \beta$ plaques of individuals with $\mathrm{AD}$ (Lovell et al., 1998). Indeed, A $\beta 1-42$ possesses high affinity for these transition metals and the binding promotes assembly of $\mathrm{A} \beta$ (Atwood et al., 1999). The inverse correlation may reflect a possible antioxidant property of $A \beta$ peptide that chelates copper and iron to keep these transition metals in a redox-inactive form (Kontush, 2001; 
Zou et al., 2002). Another possible explanation is that the inverse correlation may reflect zinc elevation as a homeostatic antioxidant response to oxidative stress with subsequent abundant $\mathrm{A} \beta$ plaques formation (Cuajungco et al., 2000). Because recent studies have suggested that pre-fibrillar A $\beta$, but not the A $\beta$ fibril, shows toxicity (Lambert et al., 1998; Walsh et al., 1999), $\mathrm{A} \beta$ plaques themselves may represent a fraction of total $\mathrm{A} \beta$ in the brain that has been condensed and neutralized and no longer contributes to neurotoxicity. Further investigations on the relationship between intraneuronally accumulated $A \beta$ (Gouras et al., 2000) and oxidative stress markers are necessary to elucidate whether intraneuronal $\mathrm{A} \beta$ peptide has pro- or antioxidant property. 


\section{Conclusion}

We observed prominent nucleic acid oxidation marked by $80 \mathrm{OHG}$ immunoreactivity in FAD patients with PS-1 or A $\beta$ PP gene mutation. The $8 \mathrm{OHG}$ was mainly restricted to cytoplasmic RNA of vulnerable neurons in FAD as we observed in sporadic AD. Early involvement of RNA oxidation in the pathological cascade of FAD was suggested by a presymptomatic case who carried a PS-1 mutation and showed a considerable level of neuronal RNA oxidation. An inverse correlation of $\mathrm{A} \beta 42$ burden with neuronal RNA oxidation in FAD, which was demonstrated also in Down syndrome, might suggest a link between the process of $A \beta$ plaques formation and an effective tissue protective response to oxidative stress.

\section{Acknowledgments}

Work in the authors' laboratories is supported by funding from the Japan Society for the Promotion of Science (Grant-in-Aid for Scientific Research (c) 14570902), Alzheimer Association, and National Institute of Health. 


\section{References}

Atwood, C.S., Huang, X., Moir, R.D., Tanzi, R.E., Bush, A.I., 1999. Role of free radicals and metal ions in the pathogenesis of Alzheimer's disease. Met. Ions Biol. Syst. 36, 309-64.

Bogdanovic, N., Zilmer, M., Zilmer, K., Rehema, A., Karelson, E., 2001. The Swedish APP670/671 Alzheimer's disease mutation: the first evidence for strikingly increased oxidative injury in the temporal inferior cortex. Dement. Geriatr. Cogn. Disord. 12, 364-370.

Cecchi, C., Fiorillo, C., Sorb, S., Latorraca, S., Nacmias, B., Bagnoli, S., Nassi, P., Liguri, G., 2002. Oxidative stress and reduced antioxidant defenses in peripheral cells from familial Alzheimer's patients. Free. Radic. Biol. Med. 33, 1372-1379.

Cuajungco, M.P., Goldstein, L.E., Nunomura, A., Smith, M.A., Lim, J.T., Atwood, C.S., Huang, X., Farrag, Y.W., Perry, G., Bush, A.I., 2000. Evidence that the $\beta$-amyloid plaques of Alzheimer's disease represent the redox-silencing and entombment of A $\beta$ by zinc. J. Biol. Chem. 275, 19439-19442.

Eckert, A., Steiner, B., Marques, C., Leutz, S., Romig, H., Haass, C., Muller, W.E., 2001. Elevated vulnerability to oxidative stress-induced cell death and activation of caspase- 3 by the Swedish amyloid precursor protein mutation. J. Neurosci. Res. 64, 183-192.

Gouras, G.K., Tsai, J., Naslund, J., Vincent, B., Edgar, M., Checler, F., Greenfield, J.P., Haroutunian, V., Buxbaum, J.D., Xu, H., Greengard, P., Relkin, N.R., 2000. Intraneuronal Aß42 accumulation in human brain. Am. J. Pathol. 156, 15-20.

Guo, Q., Sopher, B.L., Furukawa, K., Pham, D.G., Robinson, N., Martin, G.M., Mattson, M.P., 1997. Alzheimer's presenilin mutation sensitizes neural cells to apoptosis induced by trophic factor withdrawal and amyloid $\beta$-peptide: involvement of calcium and oxyradicals. J. Neurosci. 17, 4212-4222. 
Guo, Q., Sebastian, L., Sopher, B.L., Miller, M.W., Ware, C.B., Martin, G.M., Mattson, M.P., 1999. Increased vulnerability of hippocampal neurons from presenilin-1 mutant knock-in mice to amyloid $\beta$-peptide toxicity: central roles of superoxide production and caspase activation. J. Neurochem. 72, 1019-1029.

Hashimoto, Y., Niikura, T., Ito, Y., Kita, Y., Terashita, K., Nishimoto, I., 2002. Neurotoxic mechanisms by Alzheimer's disease-linked N141I mutant presenilin 2. J. Pharmacol. Exp. Ther. 300, 736-745.

Hyman, B.T., Marzloff, K., Arriagada, P.V., 1993. The lack of accumulation of senile plaques or amyloid burden in Alzheimer's disease suggests a dynamic balance between amyloid deposition and resolution. J. Neuropathol. Exp. Neurol. 52, 594-600.

Iwatsubo, T., Odak, A., Suzuki, N., Mizusawa, H., Nukina, N., Ihara, Y., 1994. Visualization of $A \beta 42(43)$ and $A \beta 40$ in senile plaques with end-specific $A \beta$ monoclonals: evidence that an initially deposited species is A $\beta 42(43)$. Neuron 13, 45-53.

Jenner, P., 1998. Oxidative mechanisms in nigral cell death in Parkinson's disease. Mov. Disord. 13 Suppl 1, 24-34.

Kalaria, R.N., Cohen, D.L., Greenberg, B.D., Savage, M.J., Bogdanovic, N.E., Winblad, B., Lannfelt, L., Adem, A., 1996. Abundance of the longer A $\beta 42$ in neocortical and cerebrovascular amyloid $\beta$ deposits in Swedish familial Alzheimer's disease and Down's syndrome. Neuroreport 7, 1377-1381.

Kontush, A., 2001. Amyloid- $\beta$ : an antioxidant that becomes a pro-oxidant and critically contributes to Alzheimer's disease. Free Radic. Biol. Med. 31, 1120-1131.

LaFontaine, M.A., Mattson, M.P., Butterfield, D.A., 2002. Oxidative stress in synaptosomal proteins from mutant presenilin-1 knock-in mice: implications for familial Alzheimer's 
disease. Neurochem. Res. 27, 417-421.

Lambert, M.P., Barlow, A.K., Chromy, B.A., Edwards, C., Freed, R., Liosatos, M., Morgan, T.E., Rozovsky, I., Trommer, B., Viola, K.L., Wals, P., Zhang, C., Finch, C.E., Krafft, G.A., Klein, W.L., 1998. Diffusible, nonfibrillar ligands derived from A $\beta 1-42$ are potent central nervous system neurotoxins. Proc. Natl. Acad. Sci. USA 26, 6448-6453.

Leutner, S., Czech, C., Schindowski, K., Touchet, N., Eckert, A., Muller, W.E., 2000. Reduced antioxidant enzyme activity in brains of mice transgenic for human presenilin-1 with single or multiple mutations. Neurosci. Lett. 292, 87-90.

Lippa, C.F., Nee, L.E., Mori, H., St George-Hyslop, P., 1998. A $\beta-42$ deposition precedes other changes in PS-1 Alzheimer's disease. Lancet 352, 1117-1118.

Lovell, M.A., Robertson, J.D., Teesdale, W.J., Campbell, J.L., Markesbery, W.R., 1998. Copper, iron and zinc in Alzheimer's disease senile plaques. J. Neurol. Sci. 158, 47-52.

Markesbery, W. R., Carney, J. M., 1999. Oxidative alterations in Alzheimer's disease. Brain Pathol. 9, 133-146.

Marques, C.A., Keil, U., Bonert, A., Steiner, B., Haass, C., Muller, W.E., Eckert, A., 2003. Neurotoxic mechanisms caused by the Alzheimer's disease-linked Swedish amyloid precursor protein mutation: oxidative stress, caspases, and the JNK pathway. J. Biol. Chem. 278, 28294-28302.

Matsuoka, Y., Picciano, M., La Francois, J., Duff, K., 2001. Fibrillar $\beta$-amyloid evokes oxidative damage in a transgenic mouse model of Alzheimer's disease. Neuroscience 104, 609-613.

Nunomura, A., Perry, G., Pappolla, M.A., Wade, R., Hirai, K., Chiba, S., Smith, M.A., 1999. RNA oxidation is a prominent feature of vulnerable neurons in Alzheimer's disease. J. Neurosci. 19, 1959-1964. 
Nunomura, A., Perry, G., Pappolla, M.A., Friedland, R.P., Hirai, K., Chiba, S., Smith, M.A., 2000. Neuronal oxidative stress precedes amyloid- $\beta$ deposition in Down syndrome. J. Neuropathol. Exp. Neurol. 59, 1011-1017.

Nunomura, A., Perry, G., Aliev, G., Hirai, K., Takeda, A., Balraj, E.K., Jones, P.K., Ghanbari, H., Wataya, T., Shimohama, S., Chiba, S., Atwood, C.S., Petersen, R.B., Smith, M.A., 2001. Oxidative damage is the earliest event in Alzheimer disease. J. Neuropathol. Exp. Neurol. 60, $759-767$.

Nunomura, A., Chiba, S., Kosaka, K., Takeda, A., Castellani, R.J., Smith, M.A., Perry, G., 2002 Neuronal RNA oxidation is a prominent feature of dementia with Lewy bodies. Neuroreport 13, 2035-2039 (Erratum: 2003 Neuroreport 14, 93).

Perry, G., Castellani, R.J., Hirai, K., Smith, M.A., 1998. Reactive oxygen species mediate cellular damage in Alzheimer disease. J. Alzheimer Dis. 1, 45-55.

Praticò, D., Uryu, K., Leight, S., Trojanoswki, J.Q., Lee, V.M., 2001. Increased lipid peroxidation precedes amyloid plaque formation in an animal model of Alzheimer amyloidosis. J. Neurosci. 21, 4183-4187.

Shan, X., Tashiro, H., Lin, C.L., 2003. The identification and characterization of oxidized RNAs in Alzheimer's disease. J. Neurosci. 23, 4913-4921.

Smith, M. A., Hirai, K., Hsiao, K., Pappolla, M.A., Harris, P.L., Siedlak, S.L., Tabaton, M., Perry, G., 1998. Amyloid- $\beta$ deposition in Alzheimer transgenic mice is associated with oxidative stress. J. Neurochem. 70, 2212-2215.

Smith, M.A., Rottkamp, C.A., Nunomura, A., Raina, A.K., Perry, G., 2000. Oxidative stress in Alzheimer's disease. Biochim. Biophys. Acta 1502, 139-144.

Sternberger, L.A., 1986 Immunocytochemistry. Third edition, Wiley, New York. 
Takahashi, M., Dore, S., Ferris, C.D., Tomita, T., Sawa, A., Wolosker, H., Borchelt, D.R., Iwatsubo, T., Kim, S.H., Thinakaran, G., Sisodia, S.S., Snyder, S.H., 2000. Amyloid precursor proteins inhibit heme oxygenase activity and augment neurotoxicity in Alzheimer's disease. Neuron 28, 461-473.

Walsh, D.M., Hartley, D.M., Kusumoto, Y., Fezoui, Y., Condron, M.M., Lomakin, A., Benedek, G.B., Selkoe, D.J., Teplow, D.B., 1999. Amyloid $\beta$-protein fibrillogenesis. Structure and biological activity of protofibrillar intermediates. J. Biol. Chem. 274, 45-52.

Yin, B., Whyatt, R.M., Perera, F.P., Randall, M.C., Cooper, T.B., Santella, R.M., 1995. Determination of 8-hydroxydeoxyguanosine by an immunoaffinity chromatography-monoclonal antibody-based ELISA. Free Radic. Biol .Med. 18, 1023-1032.

Zhang, J., Perry, G., Smith, M.A., Robertson, D., Olson, S.J., Graham, D.G., Montine, T.J., 1999. Parkinson's disease is associated with oxidative damage to cytoplasmic DNA and RNA in substantia nigra neurons. Am. J. Pathol. 154, 1423-1429.

Zhang, Y., Dawson, V.L., Dawson, T.M., 2000. Oxidative stress and genetics in the pathogenesis of Parkinson's disease. Neurobiol. Dis. 7, 240-250.

Zou, K., Gong, J.S., Yanagisawa, K., Michikawa, M., 2002. A novel function of monomeric amyloid $\beta$-protein serving as an antioxidant molecule against metal-induced oxidative damage. J Neurosci. 22, 4833-4841. 


\section{Figure legends}

Fig. 1. Oxidized nucleoside, $8 \mathrm{OHG}$, is abundant in vulnerable neurons in FAD. Neuronal 8OHG immunoreactivity showing cytoplasmic predominace is prominent in the frontal cortex from a case of FAD with a PS-1 gene mutation (C410Y, 55 years old) (A, B). In a case of FAD with an A $\beta$ PP gene mutation (A692G, 57 years old) (C) and in a presymptomatic case with a PS-1 gene mutation (A264E, 51 years old) (D), moderately positive 8OHG immunoreactivity is observed in neurons of the frontal cortex. Whereas, in a control case (64 years old), the neuronal $8 \mathrm{OHG}$ immunoreactivity is faint in the frontal cortex (E). Scale bars, $A=100 \mu \mathrm{m}, \mathrm{B}-\mathrm{E}=50 \mu \mathrm{m}$.

Fig. 2. RNA is a major site of nucleic acid oxidation in FAD. The immunoreaction with 1F7 antibody in FAD (A, C) is diminished greatly by the treatment with DNase-free RNase (B) but only slightly by the treatment with RNase-free DNase (D). A and B are adjacent serial sections, so are $\mathrm{C}$ and D. *indicates landmark blood vessel. The frontal cortex from a case of FAD with a PS-1 gene mutation (C410Y, 47 years old). Scale bar, $100 \mu \mathrm{m}$.

Fig. 3. Increased levels of neuronal $8 \mathrm{OHG}$ immunointensity and an inverse relationship between $\%$ area of $\mathrm{A} \beta 42$ burden and neuronal $8 \mathrm{OHG}$ immunointensity in the neocortex of FAD. Relative scale measurements reveal that the levels of $8 \mathrm{OHG}$ immunoreactivity are significantly increased in FAD cases $(n=13$, average age 59 years) compared with controls $(n=15$, average age 66 years) $(* \mathrm{p}<0.05$ by Mann-Whitney U-test). A presymptomatic case with a PS-1 gene mutation (51 years old) shows a similar level of neuronal $8 \mathrm{OHG}$ immunointensity to the average of the FAD group. Values shown are the averages with SE (A). In FAD cases, there is a significant inverse correlation of $\%$ area of $A \beta 42$ burden (B), but not $\%$ area of $A \beta 40$ burden (C), 
with the levels of $8 \mathrm{OHG}$ immunoreactivity by linear regression analysis. 

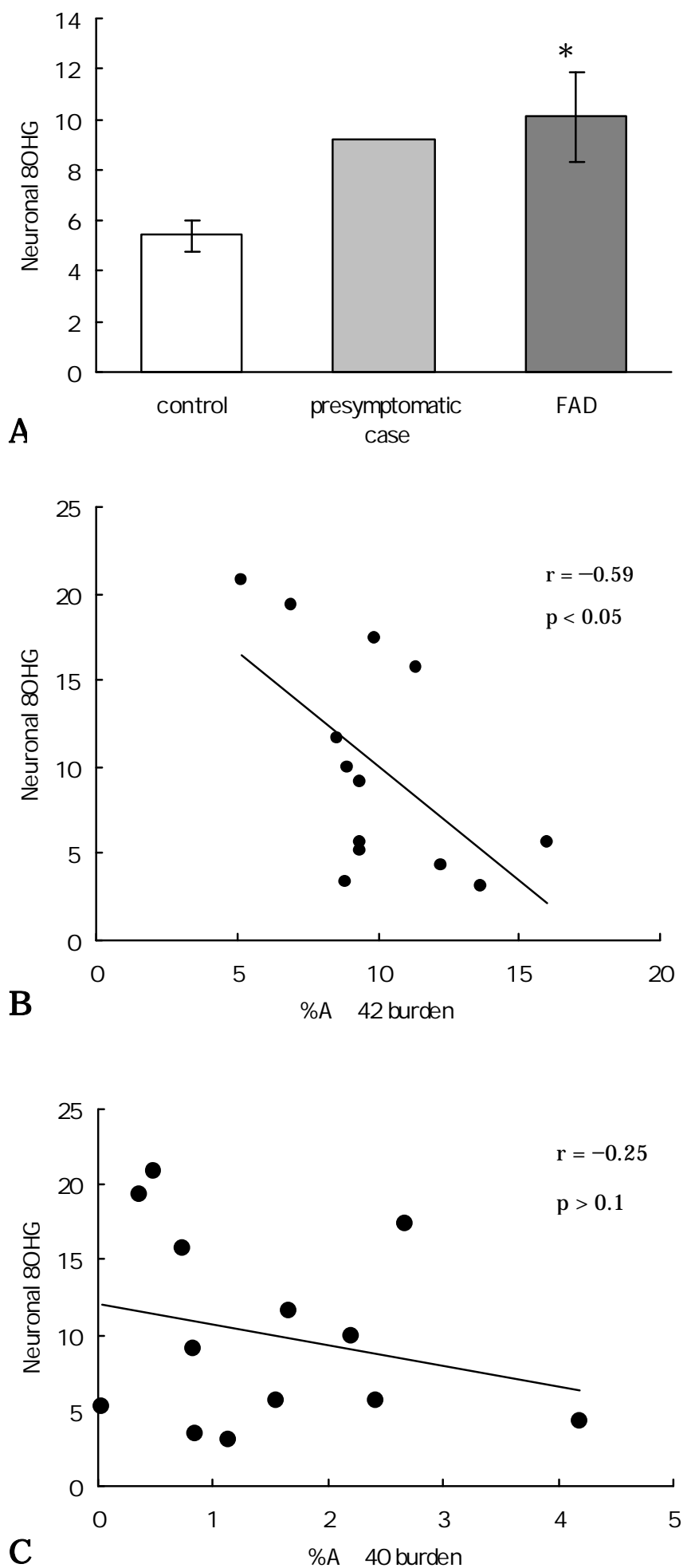

Figure 3

Nunomura, et al. 


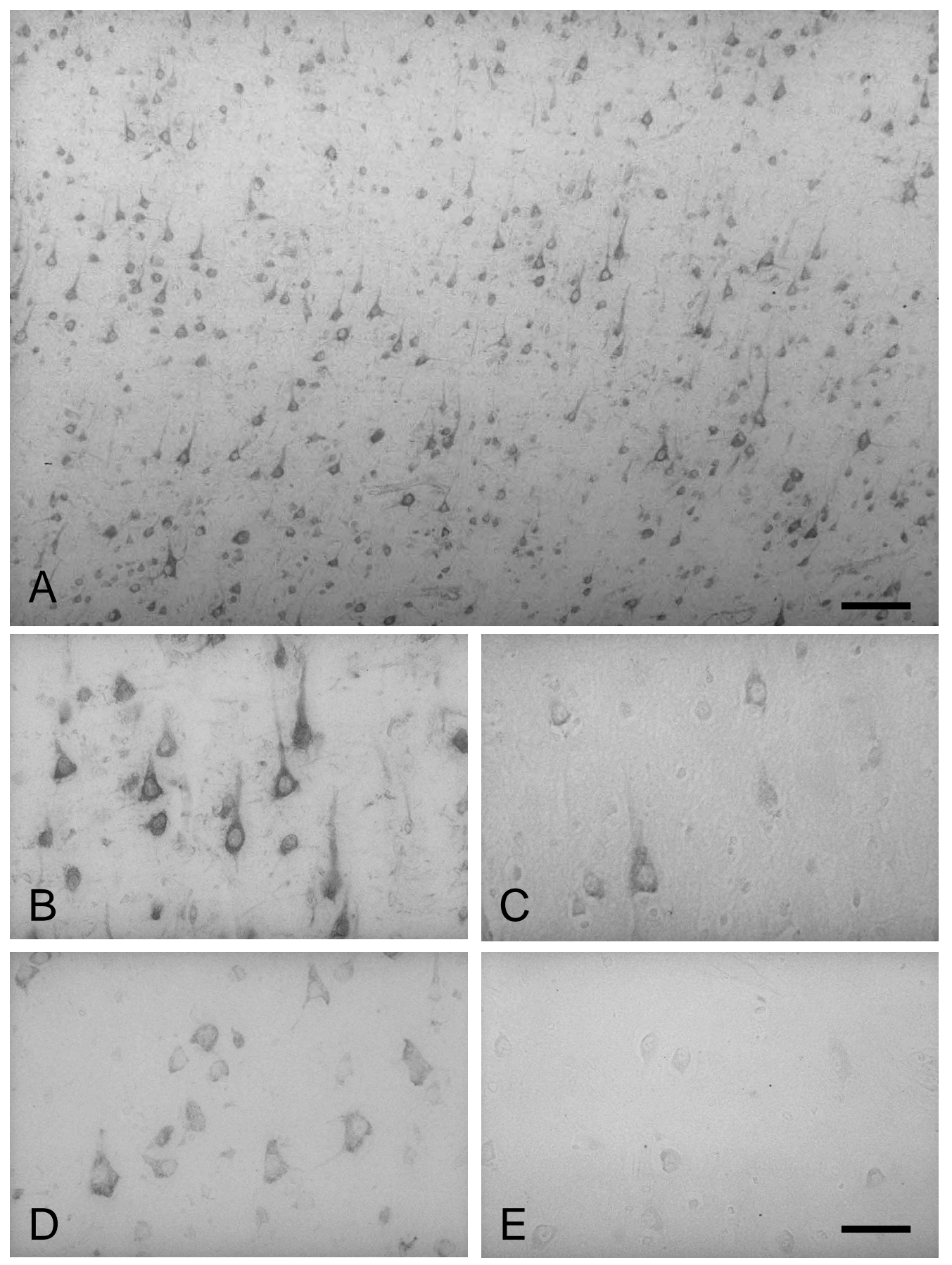




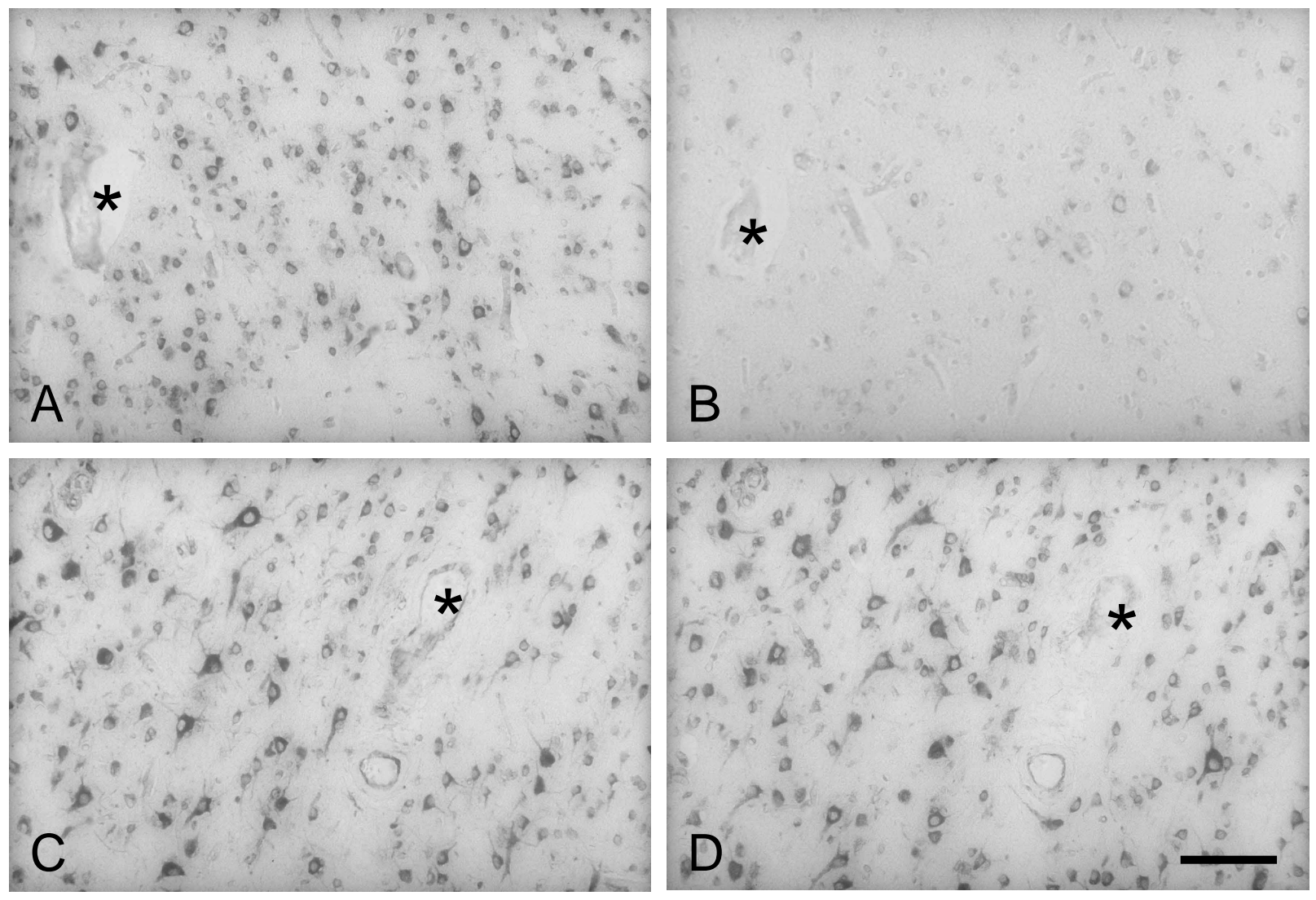

